\title{
Stream ecosystem integrity is impaired by logging and shifting agriculture in a global megadiversity center (Sarawak, Borneo)
}

\author{
Tajang Jinggut ${ }^{a}$, Catherine M. Yule ${ }^{\mathrm{a},} \square$, Luz Boyero ${ }^{\mathrm{b}, \mathrm{c}}$ \\ a School of Science, Monash University, Jalan Lagoon Selatan, Bandar Sunway, 46150, Selangor, Malaysia \\ ${ }^{\text {b } W e t l a n d E c o l o g y ~ D e p a r t m e n t, ~ D o n ̃ a n a ~ B i o l o g i c a l ~ S t a t i o n-C S I C, ~ A v d a ~ A m e r i c o ~ V e s p u c i o ~ s / n, ~ E-41092, ~ S e v i l l a, ~ S p a i n ~}$ \\ ${ }^{c}$ School of Marine and Tropical Biology, James Cook University, Townsville, Qld 4811, Australia
}

- We compare ecosystem integrity of pristine vs. logged vs. farmed streams in Borneo.

- We use both functional (leaf breakdown) and structural indicators (associated fauna).

Both practices alter ecosystem integrity, but the impacts of logging are more severe.

- Mechanized logging affects both the structure and function of stream ecosystems.

- Slash and burn clearing for shifting agriculture affects structure more than function.

Keywords:

Ecological integrity

Structural and functional indicators

Decomposition

Shredder assemblages

Farming

Logging

\begin{abstract}
a b s t r a c t
In common with most of Borneo, the Bakun region of Sarawak is currently subject to heavy deforestation mainly due to logging and, to a lesser extent, traditional slash-and-burn farming practices. This has the potential to affect stream ecosystems, which are integrators of environmental change in the surrounding terrestrial landscape. This study evaluated the effects of both types of deforestation by using functional and structural indicators (leaf litter decomposition rates and associated detritivores or 'shredders', respectively) to compare a fundamental ecosystem process, leaf litter decomposition, within logged, farmed and pristine streams. Slash-and-burn agricultural practices increased the overall rate of decomposition despite a decrease in shredder species richness (but not shredder abundance) due to increased microbial decomposition. In contrast, decomposition by microbes and invertebrates was slowed down in the logged streams, where shredders were less abundant and less species rich. This study suggests that shredder communities are less affected by traditional agricultural farming practices, while modern mechanized deforestation has an adverse effect on both shredder communities and leaf breakdown.
\end{abstract}

\section{Introduction}

Streams are sentinels and integrators of environmental change in the surrounding landscape, so by examining their condition we obtain critical information on the ecological consequences of anthropogenic activities (Williamson et al., 2008). A useful approach for the investigation of stream condition is assessing ecosystem integrity (= ecological integrity) using both structural and functional indicators, which offer complementary information (Gessner and Chauvet, 2002). While structural indicators of stream condition (e.g., biological diversity or biotic indices) have been used extensively (Rosenberg and Resh, 1993), the use of functional indicators is relatively novel (Gessner and Chauvet, 2002). Certain ecological processes such as leaf litter decomposition have proved useful as

Corresponding author. Tel.: +60 35514 6104; fax: +60 355146099

E-mail address: catherine.yule@monash.edu (C.M. Yule). functional indicators, mostly in temperate and boreal regions of the planet (e.g. Hladyz et al., 2010; McKie and Malmqvist, 2009).

Here we used structural and functional indicators of ecosystem integrity in conjunction to assess the condition of streams flowing through degraded areas in Borneo. Although this island is one of the few megadiversity centers of the world, and holds a highly endemic flora and fauna (over 15,000 species of flowering plants, 3000 species of trees and 640 species of vertebrates) (MacKinnon et al., 1998), it also has one of the highest rates of deforestation on the planet. In the Malaysian state of Sarawak, over $50 \%$ of the original forest area has been destroyed in the past 50 years and more than 300,000 ha disappear annually (King, 1993).

Until recently most of the island was forested, and the indigenous inhabitants (the Dayaks and Orang Ulu) traditionally relied on slashand-burn agriculture to cultivate hill rice (dry land rice) and other minor crops. Evidence of major forest clearing in Borneo, indicating shifting agriculture, dates back over 2500 years (Maloney, 1985) and 
even today it is still widely practiced. Originally clearing the forests (areas of about 1 ha at a time) with stone tools and fire, farmers now use chainsaws followed by fire to leave a carpet of nutrient rich ash for planting crops. The soil is not plowed, rather seeds and cuttings are planted using dibble sticks, resulting in minimal disturbance and erosion, and there is no use of fertilizers, pesticides or irrigation. Fields are abandoned after about three years, but the fallow cycle varies depending on population pressures and the availability of land, so growing populations are resulting in decreasing fallow periods. Increasingly shifting agriculture is becoming less common as logging is destroying the forests where it was previously practiced, and permanent crops are predominating (Bruun et al., 2009; Hansen, 2005).

Between 2000 and 2010, a total of 1.8 million hectares were estimated to have been deforested, representing a $10.7 \%$ decline in the total forested area of East Malaysia (Miettinen et al., 2011). Today, deforestation in Borneo is mainly due to mechanized logging, increasingly preceding conversion to oil palm plantations, but much of the deforested land is simply abandoned following logging (Curran et al., 2004). Logging and agricultural conversion to oil palms in Sarawak are undertaken as a result of government policies (Hansen, 2005). Between 2005 and 2007, $1.89 \%$ of the forest was cleared, and this increased to $2.14 \%$ from 2009 to 2010, a rate 3.5 times that of all of Asia (SarVision, 2011), due to both legal and illegal logging.

We predicted that (1) both slash-and-burn farming and logging would impair the ecological condition of streams, and (2) the consequences of logging would be more marked than those of farming because of its more destructive nature. We tested these hypotheses by examining the characteristics of shredder assemblages (as a structural indicator) and the rates of leaf litter decomposition (as a functional indicator) in streams subject to farming and logging compared to pristine streams in Sarawak. The shredders are a group of detritivores that feed on leaf litter and thus are key decomposition agents in streams (Hieber and Gessner, 2002) and a crucial link between the terrestrial and aquatic food webs (Wallace et al., 1997). We chose decomposition as a functional indicator because most headwater streams are heterotrophic systems, fueled by in-stream processing of terrestrial detrital inputs (Wallace et al., 1997), and because the effectiveness of this process as an indicator of ecological integrity has already been demonstrated (Young et al., 2008).

\section{Material and methods}

\subsection{Study area}

The study was conducted in the Bakun region of Sarawak, Borneo (Fig. 1). The climate is humid tropical with high temperatures $\left(22-33^{\circ} \mathrm{C}\right.$ ), heavy rainfall (4070 $\mathrm{mm}$ per annum) and high humidity
(35-88\%) all year round, although rains are more intense in NovemberDecember and March-April (Department of Irrigation, Sarawak). The study sites were located within the Sungai Asap resettlement scheme, $50 \mathrm{~km}$ from the Bakun Hydroelectric Power Dam, which includes pristine areas and areas subject to both farming and logging. Our study sites were one $50-\mathrm{m}$ reach in each of two pristine stream sites (Sg. Belian and Sg. Rusan), two 'farmed' sites (Sg. Lavek and Sg. Lit) and two 'logged' sites (Sg. Makabun and Sg. Kecil) (Fig. 1). The farmed and logged sites were sampled immediately downstream of the disturbance. It was not possible to sample the farmed sites in situ because the streams were completely covered by fallen trees and debris preventing access. The sites were all lowland (134-282 $\mathrm{m}$ asl) with similar characteristics in terms of original riparian vegetation (lowland dipterocarp forest), channel morphology (alternating riffles and pools) and substrate (dominated by cobbles and gravel). Clearing for shifting agriculture and mechanized logging both result in destruction of the riparian vegetation (no buffer zones are retained in either practice in the region), thus leaves entering the streams are not freshly abscised, instead they are from the debris created by tree felling. Whereas mechanized logging results in extensive substrate disturbance and massive inputs of sediment into the streams, sedimentation following clearing for agriculture is relatively minor.

\subsection{Shredder assemblages}

In August 2008 we collected ten leaf litter samples from each site. Although shredders are often more common in pools (Cheshire et al., 2005), they are generally abundant in riffles of Malaysian streams because leaf litter tends to accumulate against cobbles and boulders, particularly during elevated flows that accompany the regular high rainfall events (Yule et al., 2009). For this reason, we collected five samples from each habitat type. Sampling consisted of collecting a $20 \times 20 \mathrm{~cm}$ area of leaf litter from the substrate using a $250 \mu \mathrm{m}$-mesh dip net. Invertebrates were carefully separated from the litter and preserved in $70 \%$ ethanol. Invertebrates were sorted under a stereo microscope and identified to the lowest possible taxonomic level using available taxonomic keys (Yule and Yong, 2004).

In the laboratory, we examined invertebrate gut contents to identify shredders (whose gut contents were mainly composed of leaf and wood fragments $>1 \mathrm{~mm}$ ). Gut contents were removed under $40 \times$ magnification onto a glass slide before being mounted with polyvinyl alcohol-lactophenol. Using a compound microscope we estimated the $\%$ of plant tissue in the guts (which was nearly $100 \%$ in all specimens that were classified as shredders). Only shredders were considered for further analyses because (1) shredders break down the leaf litter and thus they are structural indicators of stream conditions

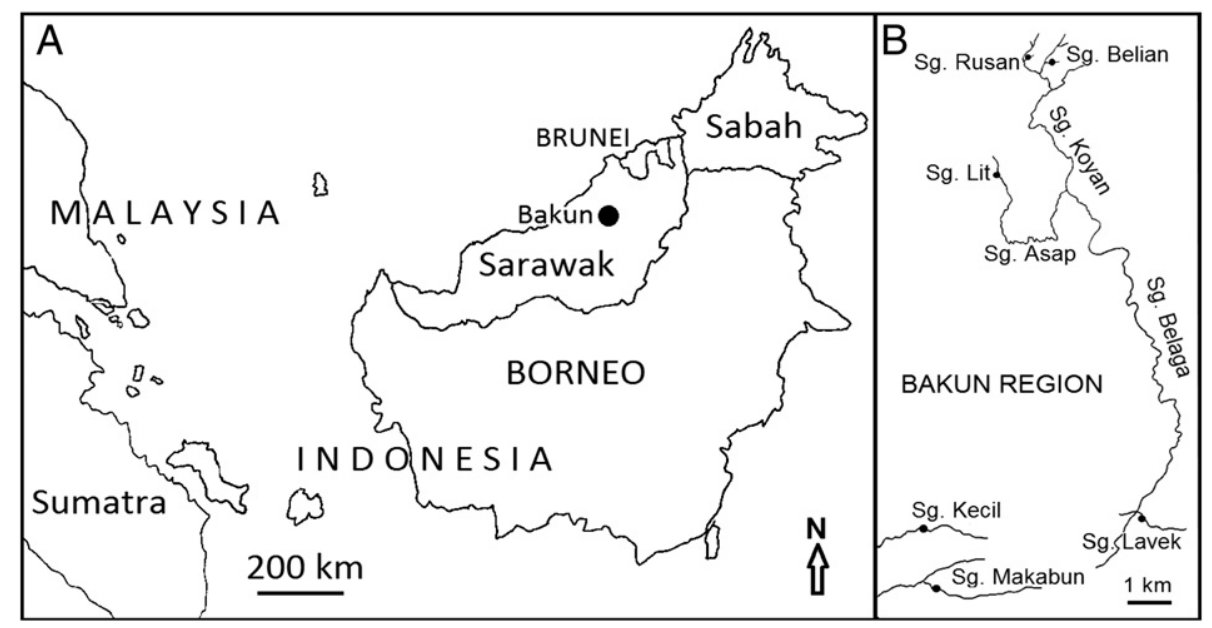

Fig. 1. A. Map of the Malaysian region. B. Location of the study sites in the Bakun Region, Sarawak. 
with respect to decomposition, and (2) other functional feeding groups (collectors, scrapers and predators) are found across a range of stream microhabitats and their presence in the leaf litter is not directly related to the decomposition process.

Litter samples were stored in separate zip-lock bags and kept cool for further laboratory analysis. The samples were then removed from the zip-lock bags and leaf toughness was determined, using a penetrometer, as the pressure required for a pin to pierce the leaf (measured using a beaker of water), in 50 random leaves per site (combining all samples from each site; 3 measurements per leaf). Leaves were then air dried, and weighed to estimate leaf litter biomass (g per sample). We then quantified the proximate total fiber content (TFC) and total phenolic content (TPC) of leaves from each sample (methods used are described in the Supplementary material).

At each study site we recorded several variables to characterize water chemistry, channel dimensions, and riparian and leaf litter characteristics. Water temperature $\left({ }^{\circ} \mathrm{C}\right)$, conductivity $\left(\mu \mathrm{S} \mathrm{cm}{ }^{-1}\right)$ and $\mathrm{pH}$ were measured with a TPS WP-81 multiparameter meter. Dissolved oxygen concentration (ppm) was measured with a Mettler-Toledo oxymeter. Stream width was measured at six transects, one every $10 \mathrm{~m}$; within these transects, water depth was measured at five regular intervals, along with the presence or absence of leaf litter, which was used to estimate the \% of substrate covered by leaf litter. Finally, we visually estimated riparian canopy cover using a \% cover grid and we measured altitude with a GPS (m asl).

\subsection{Leaf litter decomposition}

A leaf litter decomposition experiment was conducted in November and December 2008, at one pristine site (Sg. Rusan), one farmed site (Sg. Lavek), and one logged site (Sg. Kecil). Streams within each type were quite similar (see Appendix A), so we chose to use only one stream of each type as a compromise between representativeness of results and effort. Similarly, due to logistic constraints we chose to use mixed species leaf bags rather than a range of single species. We chose a mixture of leaves of typical riparian plant species that we thought would represent natural conditions better than one single species. Some previous studies (e.g. Lecerf et al., 2011) found no significant difference between decay rates of mixed species litter bags and the rates predicted by the individual component species. We used leaves of three local plant species, endemic to Malesian forests (Malaysia and Indonesia) and prevalent in stream leaf litter: Macaranga tanarius (L.) Muell. Arg. (Euphorbiaceae), a common species in gaps and secondary forests with soft palatable leaves; Gigantochloa scortechinii Gamble (Poaceae), a bamboo; and Dipterocarpus elongatus Korth (Dipterocarpaceae), a species typical of pristine forests with very tough leaves. Senescent leaves were collected from the Ampang Forest Reserve and the Forestry Research Institute Malaysia, air-dried for $48 \mathrm{~h}$, and enclosed in either coarse-mesh $(10 \mathrm{~mm})$ or fine-mesh $(0.5 \mathrm{~mm})$ bags $(\sim 1 \mathrm{~g}$ of each species per bag). Thirty-six bags (18 of each mesh type) were deployed at each site and secured using ropes attached to the riparian vegetation or the substrate. Three bags from each type were retrieved at each of six dates: days 0 (to determine weight losses due to handling), 7, 14, 21, 28 and 35. Bags were collected with a 0.5-mm mesh net placed immediately downstream to avoid loss of invertebrates and leaf fragments. Invertebrates were carefully separated from the litter in coarse-mesh bags and preserved in 70\% ethanol, while leaves and leaf fragments from bags were stored in separate zip-lock bags and kept cool for further analysis. Invertebrates were sorted under a stereo microscope and identified to the lowest possible taxonomic level using available taxonomic keys (Yule and Yong, 2004) and only shredders
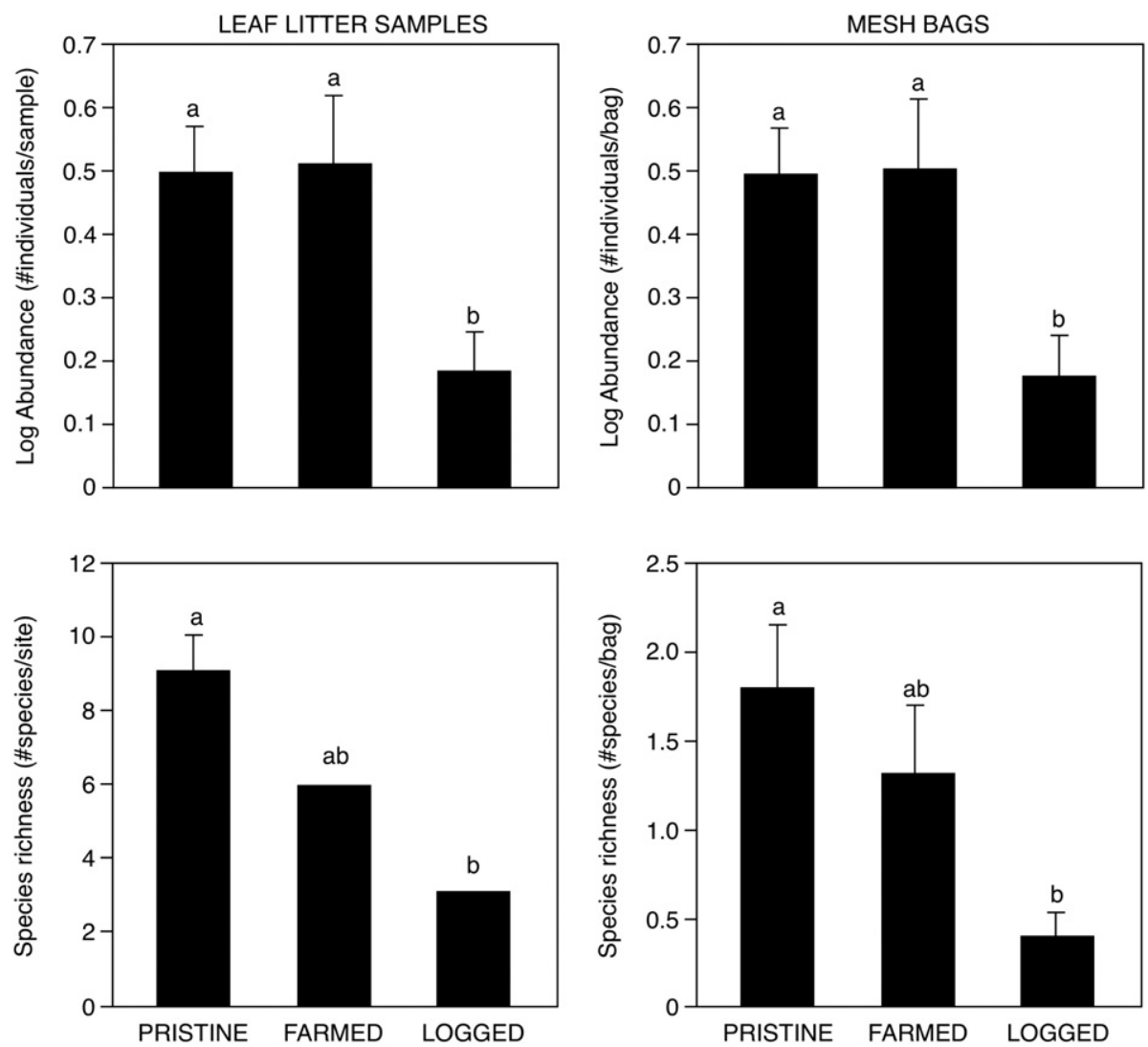

Fig. 2. Mean \pm SE shredder abundance (number of individuals per sample, transformed to the $\log [\mathrm{x}+1]$ ) and species richness (number of species per site) at our pristine, farmed and logged study sites for the leaf litter samples and the colonized mesh bags (columns with the same letter do not significantly differ — post hoc Tukey tests). 
were considered for further analyses (see above). Leaves were cleaned, air-dried for $48 \mathrm{~h}$ and kept dry until brought back to the laboratory, where they were oven-dried at $60{ }^{\circ} \mathrm{C}$ for $48 \mathrm{~h}$ and weighed.

\subsection{Statistical analyses}

We used general linear models (GLMs) to test for differences in shredder abundance (number of individuals per sample, transformed to the $\log [\mathrm{x}+1])$ and species richness (number of species per site) across stream types (pristine, farmed and logged); abundance was compared across stream types with stream site as a nested factor, to account for variation within each stream type; habitat type (riffle or pool) and leaf litter biomass were initially included in the model as covariates, but were finally removed because they had no effect ( $p 0.05$ in all cases); when a model was significant, Tukey tests were used for post hoc comparisons. Non-metric multidimensional scaling (NMDS) ordination was used to explore variation in the composition of shredder assemblages across sites; goodness of fit of the ordination was assessed by the magnitude of the associated stress value (a value of b0.2 corresponds to a good ordination; Kashian et al., 2007); we tested the hypothesis of differences in assemblage composition across stream types with Analysis of Similarities (ANOSIM), based on abundance data per sample. Principal Component Analysis (PCA) was used to summarize variation in environmental, riparian and leaf litter variables; Spearman correlations were used to explore relationships between these variables and the first two PCs (which accounted for most variation); finally, we used these two PCs in GLMs to test for environmental differences across stream types.

We used a negative exponential decay model to describe leaf litter decomposition. The natural logarithm of the proportion of leaf dry mass remaining was regressed against elapsed time in days, and the slope of the regression taken as the decomposition rate (k). We further used separate models to calculate the decomposition rate for fine $\left(\mathrm{k}_{\mathrm{f}}\right)$ and coarse mesh bags $\left(\mathrm{k}_{\mathrm{c}}\right)$, and compared these and the $k_{c} / k_{f}$ coefficient across stream types, as well as the $k_{i} / k_{r}$ coefficient ( $\mathrm{k}$ for impacted and reference sites, respectively) (Gessner and Chauvet, 2002). Finally, we used GLMs to compare shredder abundance (number of individuals per bag, transformed as above) and species richness (number of species per bag) in coarse-mesh bags among stream types (pristine, logged and farmed) and across sampling dates (7, 14, 21, 28 and 35 days); Tukey tests were again used for post hoc comparisons. Analyses were run on R 2.14.0 for MacIntosh (R Development Core Team, Vienna, Austria) and JMP 9.0 for MacIntosh (SAS Institute, Cary NC).

\section{Results}

Environmental, riparian and leaf litter characteristics of study sites are summarized in Appendix A, and a list of shredder species and their abundances is given in Appendix B. We collected 267 shredder specimens belonging to 19 species. Stream types differed in shredder abundance, which was lower at the logged than the pristine or farmed sites, and in shredder species richness, which was higher at the pristine than at the logged sites, with intermediate values for the farmed sites (Fig. 2, Table 1). The NMDS produced a twodimensional solution (stress 0.0006 ), with axis 1 separating farmed from logged sites and axis 2 separating pristine sites from the other two stream types (Fig. 3). The ANOSIM showed significant differences in shredder assemblage composition across stream types $(\mathrm{R}=0.49$, $\mathrm{p}=0.001$ ); differences between pristine and farmed sites were significant $(\mathrm{R}=0.57, \mathrm{p}=0.001)$ and so were differences between pristine and logged sites $(\mathrm{R}=0.33, \mathrm{p}=0.004)$ and between farmed and logged sites $(\mathrm{R}=0.53, \mathrm{p}=0.001$ ). Ten species ( 4 beetles, 3 dipterans, 2 stoneflies and 1 isopod) were present only in pristine sites, while 3 other species ( 2 beetles and 1 dipteran) were shared by pristine and either farmed or logged sites, and a single species (a semi-terrestrial cockroach) was
Table 1

Differences in shredder abundance (log[x+1]-transformed) and species richness in leaf litter samples across stream types (pristine, farmed and logged) and in coarse mesh bags at different experimental times and stream types; tested by general linear models (degrees of freedom, sum of squares, F-statistic and p-values shown).

\begin{tabular}{lrrrl}
\hline Source & df & \multicolumn{1}{c}{ SS } & \multicolumn{1}{c}{ F } & \multicolumn{1}{c}{$\mathrm{p}$} \\
\hline Log abundance in leaf litter samples & & & & \\
$\quad$ Stream type & 2 & 2.64 & 17.89 & 0.022 \\
$\quad 3$ & 0.22 & 0.45 & 0.71 \\
$\quad$ Stream (stream type) & 54 & 8.64 & & \\
$\quad$ Error & & & & \\
Species richness in leaf litter samples & 2 & 36.00 & 27.00 & 0.012 \\
$\quad$ Stream type & 3 & 2.00 & & \\
$\quad$ Error & 2 & 1.04 & 6.74 & 0.004 \\
Log abundance in coarse mesh bags & 4 & 0.48 & 1.55 & 0.21 \\
$\quad$ Stream type & 8 & 1.68 & 2.72 & 0.022 \\
$\quad$ Time & 30 & 2.32 & & \\
$\quad$ Stream type $\times$ time & & & & \\
$\quad$ Error & 2 & 15.24 & 5.81 & 0.007 \\
Species richness in coarse mesh bags & 4 & 3.02 & 0.58 & 0.68 \\
$\quad$ Stream type & 8 & 16.98 & 1.62 & 0.16 \\
$\quad$ Time & 30 & 39.33 & & \\
$\quad$ Stream type $\times$ time & & & & \\
$\quad$ Error &
\end{tabular}

present across all stream types. Finally, 5 species (1 beetle, 2 dipterans and 2 stoneflies) were absent from pristine sites and present at the farmed or logged sites or both (Appendix B).

Stream types showed clear differences in environmental, riparian and leaf litter characteristics. The first PC accounted for $53.8 \%$ of the variation and separated the pristine sites from the farmed and logged sites (Fig. 4), variation being significant $\left(\mathrm{F}_{2,3}=16.18, \mathrm{p}=0.031\right)$. The variables most related to PC1 pertained to water chemistry (temperature, conductivity and $\mathrm{pH}$, which increased towards farmed and logged sites, and dissolved oxygen, which increased towards pristine sites) and riparian and leaf litter characteristics (canopy cover and substrate covered by leaf litter, which increased towards pristine sites) (Appendix A). The second PC accounted for $18.8 \%$ of the variation and separated the farmed sites from the logged sites, although differences were not significant $\left(\mathrm{F}_{2,3}=1.28, \mathrm{p}=0.40\right)$. The variable

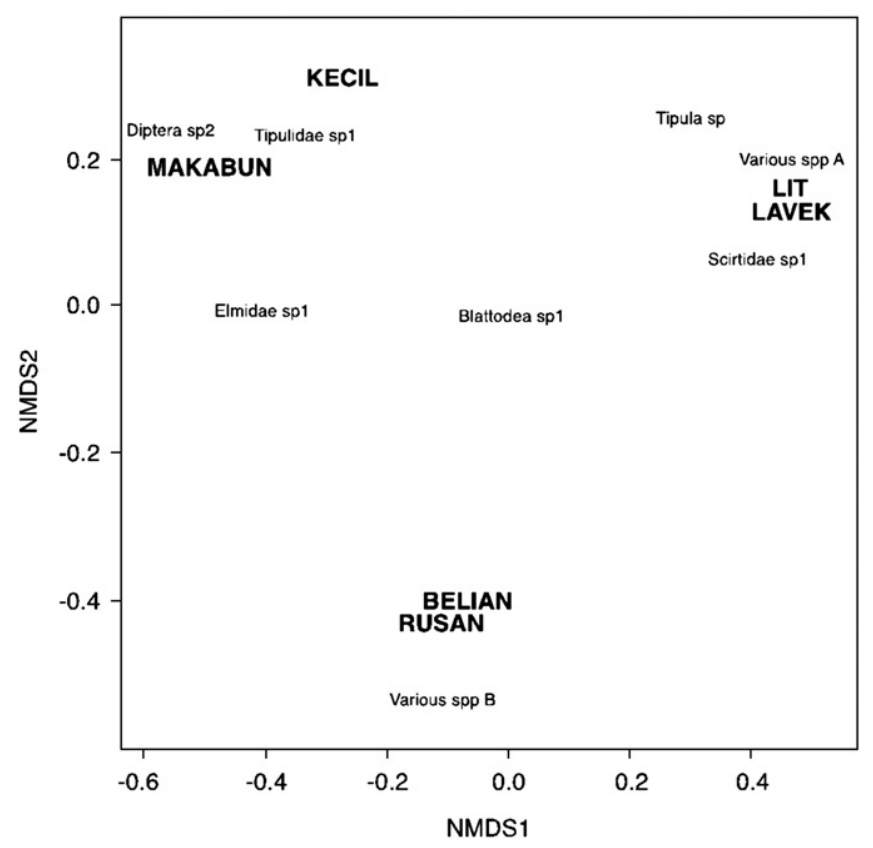

Fig. 3. Non-metric multidimensional scaling ordination of study sites and shredder species based on a two-dimensional solution (stress $=0.0006$ ). Various spp. A=Lara sp., Peltoperlopsis sp., Sphaeronemura sp.; various spp. B=Eulichadidae sp., Elmidae sp. 2, Elmidae sp. 3, Coleoptera sp., Tipulidae sp. 2, Holorusia sp., Diptera sp. 1, Cryptoperla sp. 1, Lepidostoma sp., Stenasellus sp. (not shown in the figure because they overlap). 


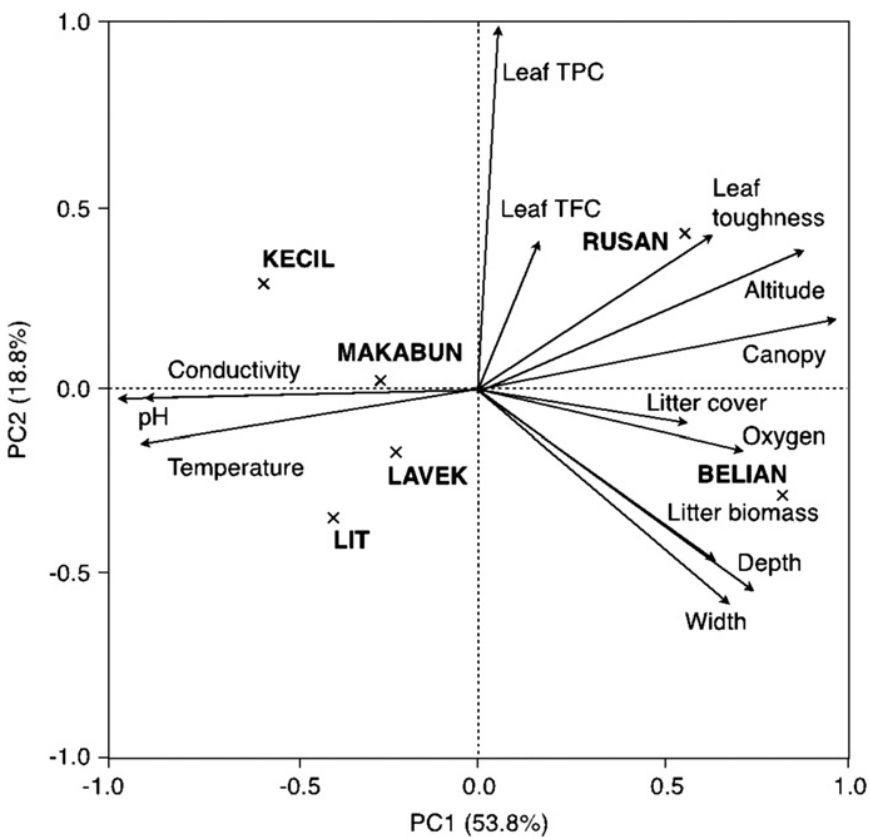

Fig. 4. Principal component analysis on environmental and leaf litter characteristics of study sites. Variation explained by each axis $\left(r^{2}\right.$, expressed as a percentage) is shown.

most related to PC2 was leaf litter TPC, which increased slightly towards the logged sites (Appendix A, Fig. 4).

Within the mixed litter bags, the Macaranga leaves were observed clearly to decompose faster than bamboo, which decomposed faster than the dipterocarp leaves. The natural logarithm of the proportion of leaf mass remaining decreased with time and was higher in fine mesh bags in the pristine and farmed streams, i.e. decomposition was slower in fine mesh bags than in coarse mesh bags at all sites except the logged site (Fig. 5). The decomposition rate in both fine $\left(\mathrm{k}_{\mathrm{f}}\right)$ and coarse $\left(\mathrm{k}_{\mathrm{c}}\right)$ mesh bags was highest at the farmed site and lowest at the logged site. As indicated by the relationship between both rates $\left(k_{\mathrm{c}} / \mathrm{k}_{\mathrm{f}}\right.$ coefficient), the relative contribution of shredders to decomposition was highest at the pristine site $(\mathrm{kc} / \mathrm{kf}=1.98)$ and lowest at the logged site $(\mathrm{kc} / \mathrm{kf}=0.78)$, although the overall rates of decomposition $\left(\mathrm{k}_{\mathrm{c}}\right)$ were highest at the farmed site (Fig. 6). Comparing the ratios of decomposition rates between the impacted sites $\left(\mathrm{k}_{\mathrm{i}}\right)$ and the pristine (reference) site $\left(\mathrm{k}_{\mathrm{r}}\right)$ (Gessner and Chauvet, 2002), the farmed site showed no impact on overall breakdown $\left(\mathrm{k}_{\mathrm{i}} / \mathrm{k}_{\mathrm{r}}=1.29\right)$ whereas the impact on the logged site was severe $\left(k_{i} / k_{r}=0.3\right)$ (Fig. 6). Conversely, the impact on microbial decomposition was evident at the farmed site $\left(\mathrm{k}_{\mathrm{i}} / \mathrm{k}_{\mathrm{r}}=1.99\right)$, but not at the logged site $\left(\mathrm{k}_{\mathrm{i}} / \mathrm{k}_{\mathrm{r}}=0.78\right)$.

Shredder abundance and species richness in leaf litter bags varied across stream types (Fig. 2). Abundance was higher at the pristine and farmed than the logged site, and richness was higher at the pristine than the logged site, while the farmed site had intermediate values. The interaction stream type $\times$ time was significant for abundance, but the only difference occurred at the farmed site between days 7 and 21 (Table 2).

\section{Discussion}

Here we used structural and functional indicators (shredder assemblage structure and leaf litter decomposition rates, respectively) to assess the ecosystem integrity of various streams in Borneo, which has been subjected to intensive farming (=slash-and-burn agriculture) and logging (=mechanized forest clearing). We hypothesized that these practices would impair stream ecosystem integrity, but potentially to different degrees (farming b logging).
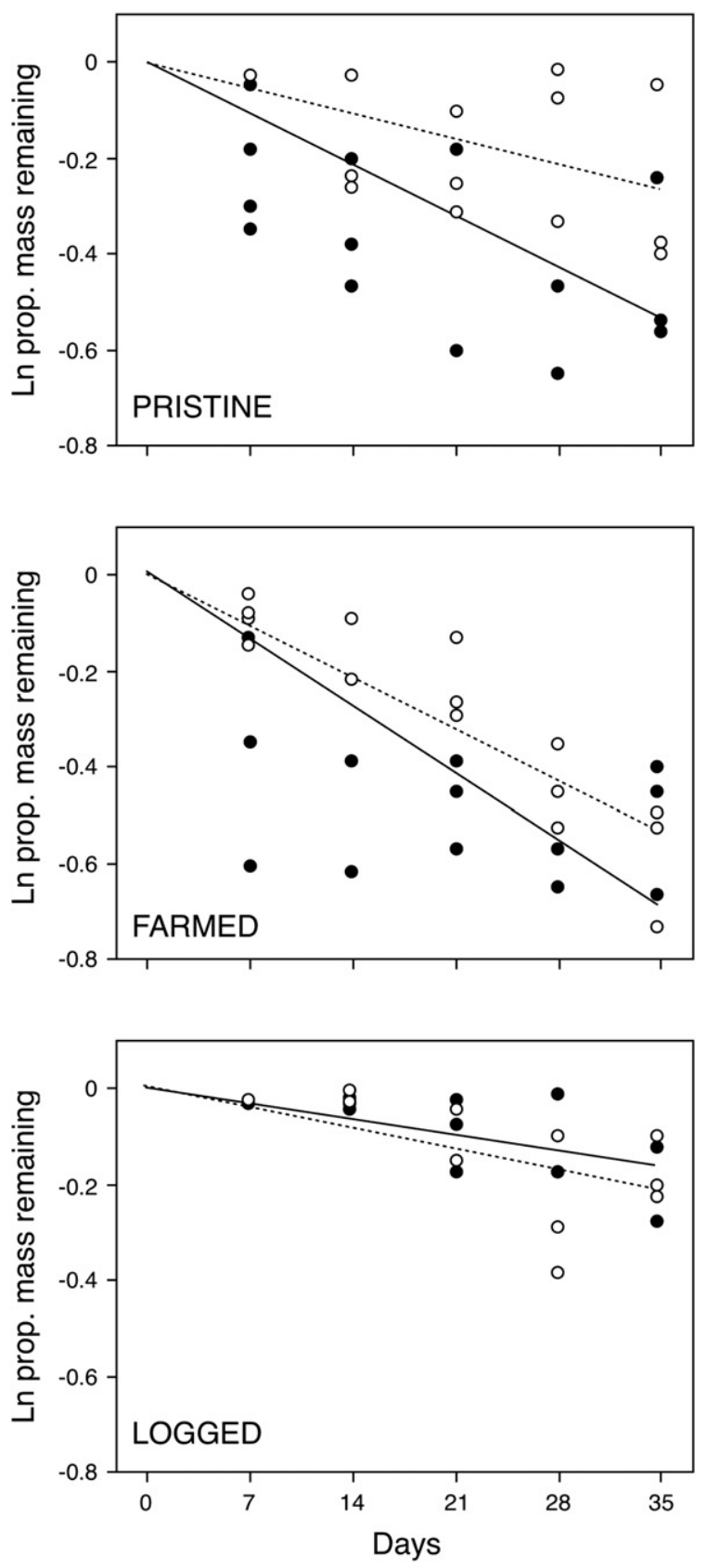

Fig. 5. Regression of the natural logarithm of the proportion of leaf dry mass remaining in fine (dotted lines, open circles) and coarse mesh bags (solid lines, solid circles) on the elapsed time (in days) at the pristine, farmed and logged study sites.

Our results confirmed both of our predictions: (1) in streams flowing through areas affected by farming and logging, shredder assemblages and decomposition rates were altered compared to those of pristine streams; and (2) the logged streams were more adversely affected than the farmed streams. We will first describe the characteristics of pristine streams in terms of shredder assemblages and decomposition rates, and then discuss the effects of each type of anthropogenic disturbance on ecosystem integrity and the potential factors responsible for such alterations.

Pristine streams showed an abundant and diverse shredder assemblage, composed of 14 species from 5 insect orders (Blattodea, Coleoptera, Diptera, Plecoptera and Trichoptera) and 1 isopod. These numbers are similar to those of lowland streams in Peninsular Malaysia, where Yule et al. (2009) found 15 shredder species of the same 5 insect orders and 1 gastropod. Malaysian streams have a rich shredder fauna, particularly 


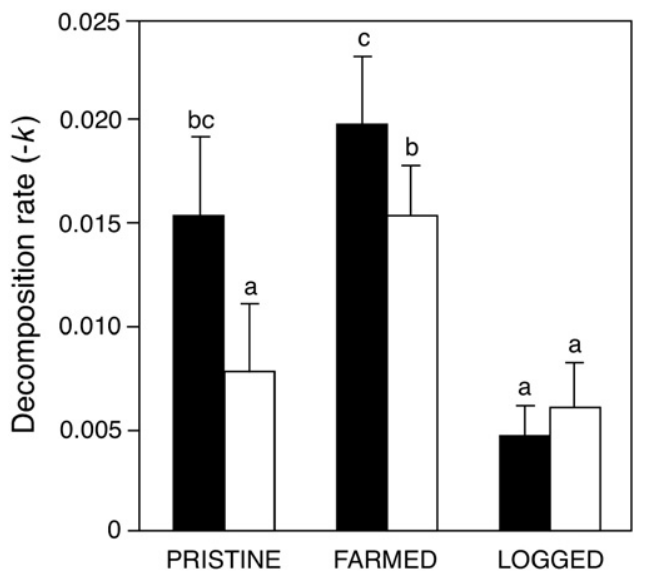

Fig. 6. Comparison of leaf decomposition rates ( \pm SE) between coarse (black bars) and fine (white bars) bags and between stream types. Decomposition rates with the same letter do not significantly differ (post hoc Tukey tests).

when compared to other tropical streams, as there is a trend for shredder assemblages to be poorer towards the equator (Boyero et al., 2011a, 2012). The contribution of shredders to leaf litter decomposition at our pristine site seemed low, as indicated by a $\mathrm{k}_{\mathrm{c}} / \mathrm{k}_{\mathrm{f}}$ coefficient of 1.98 . However, a value close to 5 has been found for decomposition of black alder leaves (Alnus glutinosa (L.) Gaertn.) at the same site (C. Yule and L. Boyero, unpubl. data), suggesting that shredder activity is high provided leaf litter is palatable. One of the species used in this experiment was a dipterocarp with tough leaves, but the other two were a bamboo and a Euphorbiaceae, with softer leaves than those of black alder (Boyero et al., 2011a). Nevertheless, leaf palatability is likely to depend on several factors including concentrations of nutrients and toxic compounds, which we did not assess in this study. As there are no data available regarding 'standard' decomposition rates for a variety of leaves, particularly for tropical regions, we concluded that a $\mathrm{k}_{\mathrm{c}} / \mathrm{k}_{\mathrm{f}}$ coefficient of 1.98 falls within the range of pristine conditions in Bornean streams. In comparison with Gessner and Chauvet's (2002) classification $\left(\mathrm{k}_{\mathrm{c}} / \mathrm{k}_{\mathrm{f}}=1.5-2\right.$, score $=1$ ), this indicates a higher contribution of shredders to leaf decomposition than in pristine temperate streams, although these authors noted that these ratios should be taken with caution when no standardization is available.

Logging caused a severe impact on breakdown by shredders in comparison with the pristine site $\left(\mathrm{k}_{\mathrm{i}} / \mathrm{k}_{\mathrm{r}}=0.3\right)$, whereas farming showed no adverse impact on shredder decomposition $\left(\mathrm{k}_{\mathrm{i}} / \mathrm{k}_{\mathrm{r}}=1.29\right)$. In fact, the overall rate of decomposition was higher at the farmed than the pristine site, particularly in the first stages of decomposition. In contrast, rates of microbial decomposition were similar between the pristine and logged sites $\left(\mathrm{k}_{\mathrm{i}} / \mathrm{k}_{\mathrm{r}}=0.78\right)$, but increased at the farmed site $\left(\mathrm{k}_{\mathrm{i}} / \mathrm{k}_{\mathrm{r}}=1.99\right)$. Fast microbial decomposition at the farmed site could be related to higher water temperature, pH and/or conductivity (Boyero et al., 2011b;

Table 2

Variation in the natural logarithm of the proportion of leaf mass remaining in experimental mesh bags depending on experimental time (in days), mesh size (fine or coarse) and stream type (pristine, farmed and logged); tested by general linear models (degrees of freedom, sum of squares, F-statistic and p-values shown).

\begin{tabular}{lrrrr}
\multicolumn{1}{c}{ Source } & df & SS & F & \multicolumn{1}{c}{$\mathrm{p}$} \\
- Ln proportion leaf mass remaining & & & & \\
$\quad$ Stream type & 2 & 1.26 & 39.22 & $\mathrm{~b} 0.001$ \\
$\quad$ Mesh size & 1 & 0.29 & 18.26 & $\mathrm{~b} 0.001$ \\
Stream type $\times$ mesh size & 2 & 0.21 & 6.60 & 0.002 \\
Time & 1 & 6.41 & 399.41 & $\mathrm{~b} 0.001$ \\
Stream type $\times$ time & 2 & 0.06 & 1.80 & 0.17 \\
Mesh size $\times$ time & 1 & 0.05 & 3.09 & 0.08 \\
Stream type $\times$ mesh size $\times$ time & 2 & 0.07 & 2.31 & 0.11 \\
Error & 80 & 1.28 & &
\end{tabular}

Young et al., 2008). Also, slashing and burning may enhance microbial communities by supplying nutrients from the ashes or by providing material which is more amenable to microbes such as green leaves.

Logged sites showed significantly reduced numbers of shredder species compared to pristine sites, and lower abundances than both pristine and farmed sites. Shredder assemblages were extremely poor, with only 3 species present per site. Decomposition was not significantly different between fine and coarse mesh bags probably because of the low numbers of shredders in coarse mesh bags, although the $\mathrm{k}_{\mathrm{c}} / \mathrm{k}_{\mathrm{f}}$ coefficient was below 1 (0.78). Farmed sites did not differ from pristine sites in terms of shredder abundance (number of individuals per leaf litter sample or per experimental leaf litter bag) or in terms of species richness per site, but pristine sites as a whole had more than twice the shredder species than farmed sites as a whole, i.e. site-to-site species replacement was higher at pristine sites. All species present at one farmed site were also present at the other site, while many species were present at only one of the pristine sites. Possibly the increased rate of decomposition at farmed sites was a result of higher microbial colonization of litter plus greater abundance of certain shredder species (e.g. the elmid Lara) that could be more effective at eating leaves (especially early in the breakdown process).

Shredder assemblages were good structural indicators of ecosystem integrity. Streams flowing through areas subject to either farming or logging showed reduced shredder diversity and a marked change in assemblage composition, with the disappearance of many species. However, abundances were only reduced at logged sites, suggesting that species living at farmed sites increased their abundance, perhaps due to release from interspecific competition (Bolnick et al., 2010) or to an increase in certain resources such as wood. Woody debris was abundant at farmed sites as a result of the land clearing activity, and larvae of Lara sp. have been reported as common in streams with high amounts of woody substrata (Andersson, 1985). It is also possible that some shredder species have evolutionarily adapted to stream conditions imposed by shifting agriculture, as this has been common in the region for thousands of years (Maloney, 1985). Mechanized logging, in contrast, is a more recent practice and may have more aggressive consequences on the stream habitat because of the massive disturbance to the catchment caused by bulldozers and other heavy equipment that results in extensive sedimentation of the stream bed. A previous study in Borneo (Yule et al., 2010) found shredders to be eliminated by sedimentation, which was clearly evident in the logged stream, where the substrate and leaf litter were blanketed with fine sediment.

Leaf litter decomposition was a good functional indicator of ecosystem integrity, as both farmed and logged sites showed altered decomposition rates when compared to the pristine site. Impaired ecosystem function at the logged site was most likely due to the reduction in shredder diversity and abundance, while both microbial decomposition and breakdown by shredders was faster at the farmed site where although fewer shredder species were found, total abundance was unaffected. Microbial decomposition was slowest at the logged site, where it was possibly impeded due to sedimentation, and fastest at the farmed site, possibly driven by increased water temperatures (due to a reduction in canopy cover and thus increased insolation; Bojsen and Jacobsen, 2003) and changes in water chemistry. Altered nutrient concentrations might also be partly responsible for increased microbial rates (Iwata et al., 2003; Young et al., 2008), but unfortunately we did not measure nutrients in this study.

Other studies have shown depauperate shredder assemblages at logged stream sites (Kreutzweiser, 2008). Moreover, whole stream invertehrate rommunitios are afferter hv lnooino in Kalimantan (Rornen)

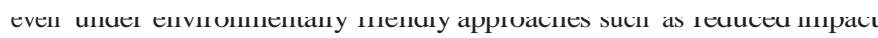
logging (Derleth, 2003). In Sarawak, our study area, logging practices are extensive and deforestation is highly mechanized, with bulldozers devastating the land (Putz et al.. 2000) and no riparian buffer zones. so consequences are potentially more severe. Unfortunately, the practice of 
shifting agriculture is declining throughout Southeast Asia, being replaced by permanent cash crops (Bruun et al., 2009; Hansen, 2005). In contrast to the small areas of land typically cleared for slash-and-burn farming, in Sarawak and elsewhere in Borneo logging and conversion to oil palm plantations is destroying enormous areas of forest (Curran et al., 2004) both in regions previously farmed and in areas that have never before been cleared. Although stream ecosystems in Borneo are resistant and probably also resilient to the effects of shifting agriculture, the impacts of logging are far more destructive to aquatic ecosystem structure and function, as shown in this study. Furthermore, since the forests are permanently destroyed by logging and agricultural conversion, the streams will most likely be permanently impaired by these practices.

\section{Conclusions}

Our study demonstrates, through the use of structural and functional indicators, that logging and farming practices alter ecosystem integrity in Bornean streams, and also that consequences are more severe in areas subject to mechanized logging than in those subject to traditional, slash-and-burn farming. Given the high levels of endemism reported for Borneo, it is likely that many aquatic invertebrate species could face extinction due to these activities. Our results suggest that logging affects both structure and function of stream ecosystems, however although slash-and-burn farming affects ecosystem structure, it does not impair ecosystem functioning with respect to leaf breakdown. As forests in Sarawak and elsewhere in Borneo are increasingly destroyed and converted to oil palm plantations, ecosystem functioning of streams is likely to become permanently impaired.

\section{Acknowledgments}

This work was part of the research for BSc Honors conducted by T.J. funded by Monash University. The study was initiated with a grant from National Geographic Society's Committee for Research and Exploration (grant number 7980-06; P.I., Luz Boyero). N. Connolly designed the penetrometer and Rob Gegg constructed it at James Cook University (Australia). L.B. was supported by a Ramón y Cajal Grant from the Spanish Ministry for Science and Innovation. The funding sources had no role in any aspects of the study apart from financial support. We wish to thank the two anonymous reviewers whose suggestions greatly improved the manuscript.

Appendix A. Geographic position, environmental and leaf litter characteristics of each study site

\begin{tabular}{|c|c|c|c|c|c|c|}
\hline & \multicolumn{2}{|l|}{ Pristine sites } & \multicolumn{2}{|l|}{ Farmed sites } & \multicolumn{2}{|l|}{ Logged sites } \\
\hline & Belian & Rusan & Lavek & Lit & Kecil & Makabun \\
\hline \multicolumn{7}{|l|}{ Geographic position } \\
\hline \multirow[t]{2}{*}{ Coordinates } & $3^{\circ} 08^{\prime} 28^{\prime \prime} \mathrm{N}$ & $3^{\circ} 08^{\prime} 42^{\prime \prime} \mathrm{N}$ & $2^{\circ} 50^{\prime} 20^{\prime \prime} \mathrm{N}$ & $2^{\circ} 50^{\prime} 17^{\prime \prime} \mathrm{N}$ & $2^{\circ} 47^{\prime} 19^{\prime \prime} \mathrm{N}$ & $2^{\circ} 49^{\prime} 19^{\prime \prime} \mathrm{N}$ \\
\hline & $113^{\circ} 56^{\prime} 23^{\prime \prime} \mathrm{E}$ & $113^{\circ} 56^{\prime} 06^{\prime \prime} \mathrm{E}$ & $114^{\circ} 01^{\prime} 04^{\prime \prime} \mathrm{E}$ & $114^{\circ} 01^{\prime} 23^{\prime \prime} \mathrm{E}$ & $114^{\circ} 01^{\prime} 19^{\prime \prime} \mathrm{E}$ & $114^{\circ} 01^{\prime} 45^{\prime \prime} \mathrm{E}$ \\
\hline Altitude (m asl) & 232 & 282 & 142 & 148 & 150 & 134 \\
\hline \multicolumn{7}{|l|}{ Channel morphology } \\
\hline Wetted stream width (m) & $7.8 \pm 1.2$ & $0.9 \pm 0.2$ & $2.0 \pm 1.2$ & $1.9 \pm 1.4$ & $0.7 \pm 0.2$ & $1.5 \pm 0.5$ \\
\hline Water depth $(\mathrm{cm})$ & $19.2 \pm 12.4$ & $6.9 \pm 3.6$ & $24.3 \pm 5.9$ & $18.4 \pm 5.1$ & $11.2 \pm 2.3$ & $24.0 \pm 5.7$ \\
\hline \multicolumn{7}{|l|}{ Water chemistry } \\
\hline Temperature $\left({ }^{\circ} \mathrm{C}\right)$ & 23.7 & 23.7 & 26.5 & 26.5 & 27.0 & 25.0 \\
\hline $\mathrm{pH}$ & 6.8 & 6.9 & 7.1 & 7.1 & 7.1 & 7.1 \\
\hline Conductivity $(\mu \mathrm{S} / \mathrm{cm})$ & 24.2 & 19.4 & 43.5 & 50.1 & 66.5 & 38.5 \\
\hline Oxygen (ppm) & 9.82 & 9.70 & 9.88 & 9.22 & 9.15 & 9.32 \\
\hline \multicolumn{7}{|l|}{ Leaf litter } \\
\hline Canopy cover (\%) & 75 & 75 & 0 & 0 & 0 & 0 \\
\hline Substrate covered (\%) & 57 & 63 & 60 & 50 & 37 & 62 \\
\hline Biomass (g/sample) & $182 \pm 84$ & $132 \pm 48$ & $80 \pm 39$ & $164 \pm 72$ & $80 \pm 26$ & $89 \pm 37$ \\
\hline Toughness $\left(\mathrm{g} / \mathrm{mm}^{2}\right)$ & $322 \pm 41$ & $366 \pm 55$ & $247 \pm 34$ & $80 \pm 39$ & $267 \pm 91$ & $51 \pm 5$ \\
\hline TPC (mg GAE/100 mg) & $264 \pm 11$ & $311 \pm 61$ & $267 \pm 91$ & $254 \pm 33$ & $303 \pm 52$ & $284 \pm 64$ \\
\hline TFC (\% dry mass) & $64 \pm 5$ & $61 \pm 5$ & $51 \pm 5$ & $50 \pm 4$ & $64 \pm 4$ & $73 \pm 9$ \\
\hline
\end{tabular}

Appendix B. Abundance (number of individuals) of shredder species found at each study site

\begin{tabular}{|c|c|c|c|c|c|c|c|c|c|}
\hline \multirow[t]{2}{*}{ Class } & \multirow[t]{2}{*}{ Order } & \multirow[t]{2}{*}{ Family } & \multirow[t]{2}{*}{ Species } & \multicolumn{2}{|c|}{ Pristine sites } & \multicolumn{2}{|c|}{ Farmed sites } & \multicolumn{2}{|c|}{ Logged sites } \\
\hline & & & & Belian & Rusan & Lavek & Lit & Kecil & Makabun \\
\hline \multirow[t]{11}{*}{ Insecta } & Blattodea & Unknown & Blattodea sp. & 13 & 25 & 2 & 11 & 6 & 0 \\
\hline & Coleoptera & Eulichadidae & Eulichadidae sp. & 0 & 1 & 0 & 0 & 0 & 0 \\
\hline & & Elmidae & Lara sp. & 0 & 0 & 48 & 23 & 0 & 0 \\
\hline & & & Elmidae sp. 1 & 2 & 0 & 0 & 0 & 0 & 2 \\
\hline & & & Elmidae sp. 2 & 0 & 2 & 0 & 0 & 0 & 0 \\
\hline & & & Elmidae sp. 3 & 0 & 1 & 0 & 0 & 0 & 0 \\
\hline & & Scirtidae & Scirtidae sp. & 4 & 0 & 3 & 10 & 0 & 0 \\
\hline & & Unknown & Coleoptera sp. & 1 & 0 & 0 & 0 & 0 & 0 \\
\hline & Diptera & Tipulidae & Tipula sp. & 0 & 0 & 2 & 6 & 1 & 0 \\
\hline & & & Holorusia sp. & 0 & 3 & 0 & 0 & 0 & 0 \\
\hline & & & Tipulidae sp. 1 & 1 & 3 & 0 & 0 & 3 & 2 \\
\hline
\end{tabular}


Appendix B (continued)

\begin{tabular}{|c|c|c|c|c|c|c|c|c|c|}
\hline \multirow[t]{2}{*}{ Class } & \multirow[t]{2}{*}{ Order } & \multirow[t]{2}{*}{ Family } & \multirow[t]{2}{*}{ Species } & \multicolumn{2}{|c|}{ Pristine sites } & \multicolumn{2}{|c|}{ Farmed sites } & \multicolumn{2}{|c|}{ Logged sites } \\
\hline & & & & Belian & Rusan & Lavek & Lit & Kecil & Makabun \\
\hline & & & Tipulidae sp. 2 & 0 & 2 & 0 & 0 & 0 & 0 \\
\hline & & Unknown & Diptera sp. 1 & 1 & 6 & 0 & 0 & 0 & 0 \\
\hline & & & Diptera sp. 2 & 0 & 0 & 0 & 0 & 0 & 4 \\
\hline & Plecoptera & Nemouridae & Sphaeronemura sp. & 0 & 0 & 1 & 3 & 0 & 0 \\
\hline & & Peltoperlidae & Cryptoperla sp. & 1 & 1 & 0 & 0 & 0 & 0 \\
\hline & & & Peltoperlopsis sp. & 0 & 0 & 25 & 12 & 0 & 0 \\
\hline & Trichoptera & Lepidostomatidae & Lepidostoma sp. & 19 & 15 & 0 & 0 & 0 & 0 \\
\hline Crustacea & Isopoda & Cirolanidae & Stenasellus sp. & 0 & 2 & 0 & 0 & 0 & 0 \\
\hline \multicolumn{4}{|c|}{ Total shredder abundance } & 42 & 61 & 81 & 65 & 10 & 8 \\
\hline \multicolumn{4}{|c|}{ Total shredder species richness } & 8 & 11 & 6 & 6 & 3 & 3 \\
\hline
\end{tabular}

\section{Appendix C. Supplementary data}

Supplementary data to this article can be found online at http:// dx.doi.org/10.1016/j.scitotenv.2012.07.062.

\section{References}

Andersson G. Decomposition of alder leaves in acid lake waters. Ecol Bull 1985;37:293-9. Bojsen B, Jacobsen D. Effects of deforestation on macroinvertebrate diversity and assemblage structure in Ecuadorian Amazon streams. Arch Hydrobiol 2003;158: $317-42$.

Bolnick DI, Ingram T, Stutz WE, Snowberg LK, Lau OL, Paull JS. Ecological release from interspecific competition leads to decoupled changes in population and individual niche width. Proc R Soc B 2010;22:1789-97.

Boyero L, Pearson RG, Dudgeon D, Graça MAS, Gessner MO, Albariño RJ, et al. Global distribution of a key trophic guild contrasts with common latitudinal diversity patterns. Ecology 2011a;92:1839-48.

Boyero L, Pearson RG, Gessner MO, Barmuta LA, Ferreira V, Graça MAS, et al. A global experiment suggests climate warming will not accelerate litter decomposition in streams but may reduce carbon sequestration. Ecol Lett 2011b;14:289-94.

Boyero L, Pearson RG, Dudgeon D, Ferreira V, Graça MAS, Gessner MO, et al. Global patterns of stream detritivore distribution: implications for biodiversity loss in changing climates. Glob Ecol Biogeogr 2012:134-41.

Bruun T, de Neergaard A, Lawrence D, Ziegler A. Environmental consequences of the demise in swidden cultivation in Southeast Asia: carbon storage and soil quality. Hum Ecol 2009;37:375-88.

Cheshire K, Boyero L, Pearson RG. Food webs in tropical Australian streams: the prevalence of shredders and predators. Freshw Biol 2005;50:748-69.

Curran LM, Trigg SN, McDonald AK, Astiani D, Hardiono YM, Siregar P, et al. Lowland forest loss in protected areas of Indonesian Borneo. Science 2004;303:1000-3.

Derleth P. Benthic invertebrates and logging activities: a case study in a lowland tropical forest in East Kalimantan. École Polytechnique Federale De Lausanne; 2003.

Gessner MO, Chauvet E. A case for using litter breakdown to assess functional stream integrity. Ecol Appl 2002;12:498-510.

Hansen TS. Spatio-temporal aspects of land use and land cover changes in the Niah catchment, Sarawak, Malaysia. Singap J Trop Geogr 2005;26:170-90.

Hieber M, Gessner MO. Contribution of stream detrivores, fungi, and bacteria to leaf breakdown based on biomass estimates. Ecology 2002;83:1026-38.

Hladyz S, Tiegs SD, Gessner MO, Giller PS, Noveanu G, Preda E, et al. Leaf-litter breakdown in pasture and deciduous woodland streams: a comparison among three European regions. Freshw Biol 2010;55:1916-29.
Iwata T, Nakano S, Inoue M. Impacts of past riparian deforestation on stream communities in a tropical rain forest in Borneo. Ecol Appl 2003;13:461-73.

Kashian DR, Zuellig RE, Mitchell KA, Clements WH. The cost of tolerance: sensitivity of stream benthic communities to UV-B and metals. Ecol Appl 2007;17:365-75.

King VT. Politik pembangunan: the political economy of rainforest exploitation and development in Sarawak, East Malaysia. Glob Ecol Biogeogr Lett 1993;3:235-44.

Kreutzweiser D. Leaf-litter decomposition and macroinvertebrates communities in boreal forest streams linked to upland logging disturbance. J N Am Benthol Soc 2008;27.

Lecerf A, Marie G, Kominoski JS, LeRoy CJ, Bernadet C, Swan CM. Incubation time, functional litter diversity, and habitat characteristics predict litter-mixing effects on decomposition. Ecology 2011;92:160-9.

MacKinnon K, Hatta G, Halim H, Mangalik A. The ecology of Kalimantan. London: Oxford University Press; 1998.

Maloney BK. Man's impact on the rainforests of West Malesia: the palynological record. J Biogeogr 1985;12:537-58.

McKie BG, Malmqvist B. Assessing ecosystem functioning in streams affected by forest management: increased leaf decomposition occurs without changes to the composition of benthic assemblages. Freshw Biol 2009;254:2086-100.

Miettinen J, Shi C, Liew S. Deforestation rates in Southeast Asia between 2000 and 2010. Glob Chang Biol 2011;17:2261-70.

Putz F, Dykstra D, Heinrich R. Why poor logging practices persist in the tropics. Conserv Biol 2000;14:951-6.

Rosenberg D, Resh V. Freshwater biomonitoring and benthic macroinvertebrates. New York: Chapman and Hall; 1993.

SarVision. Impact of oil palm plantations on peatland conversion in Sarawak 2005-2010; 2011. p. 16. The Netherlands.

Wallace J, Eggert S, Meyer J, Webster J. Multiple trophic levels of a forest stream linked to terrestrial litter inputs. Science 1997;277:102-4.

Williamson CE, Dodds W, Kratz TK, Palmer MA. Lakes and streams as sentinels of environmental change in terrestrial and atmospheric processes. Front Ecol Environ 2008;6:247-54

Young RG, Matthaei CD, Townsend CR. Organic matter breakdown and ecosystem metabolism: functional indicators for assessing river ecosystem health. J N Am Benthol Soc 2008;27:605-25

Yule CM, Yong HS. Freshwater invertebrates of the Malaysian region. Academy of Sciences Malaysia; 2004.

Yule CM, Leong MY, Liew KC, Ratnarajah L, Schmidt K, Wong HM, et al. Shredders in Malaysia: abundance and richness are higher in cool upland tropical streams. J N Am Benthol Soc 2009;28:404-15.

Yule CM, Boyero L, Marchant R. Effects of sediment pollution on food webs in a tropical river (Borneo, Indonesia). Mar Freshw Res 2010;61:204-13. 